\title{
ECODESIGN E LOGÍSTICA REVERSA NA INDÚSTRIA CALÇADISTA
}

http://dx.doi.org/10.21527/2237-6453.2021.55.11239

Recebido em: 28/7/2020

Aceito em: $15 / 4 / 2021$

\author{
Margarete Blume Vier, ${ }^{1}$ Dusan Schreiber, ${ }^{2}$ \\ Vanusca Dalosto Jahno, ${ }^{2}$ Cristiane Froehlich ${ }^{2}$
}

\section{RESUMO}

O setor calçadista gera uma quantidade expressiva de resíduos poluentes e o reaproveitamento de materiais ainda é incipiente. Parte dos resíduos gerados no processo produtivo desse setor tem como destinação final os aterros industriais e o coprocessamento. Diante disso, não basta reduzir a geração, é necessário buscar alternativas para a não geração de resíduos, observando-se que a economia circular é um meio para se alcançar este objetivo. Entre os pilares da economia circular, o ecodesign e a logística reversa são os mais importantes para que se tenha a circularidade dos produtos e o reaproveitamento do material. Nesse contexto, o estudo tem por objetivo analisar a aplicação da logística reversa e do conceito de ecodesign no desenvolvimento do calçado no setor calçadista brasileiro. Quanto à metodologia, a pesquisa classifica-se em descritiva, estudo de caso múltiplo qualitativo. Os resultados evidenciam que o setor calçadista não adota a logística reversa e não aplica o conceito de ecodesign no desenvolvimento do calçado. A percepção do setor é que o calçado não apresenta impactos ambientais; além disso, em razão da dificuldade de reaproveitamento do produto, não há o interesse por parte das empresas em viabilizarem o retorno do calçado ao fabricante.

Palavras-chave: Design sustentável. Gestão de resíduos. Reaproveitamento. Setor calçadista. Sustentabilidade ambiental.

\section{ECODESIGN AND REVERSE LOGISTICS IN THE FOOTWEAR INDUSTRY}

\section{ABSTRACT}

The footwear sector generates a significant amount of polluting waste and the reuse of materials is still incipient. Part of the waste generated in the production process of this sector, is destined for industrial landfills and co-processing. Given this, it is not enough to reduce generation, it is necessary to seek alternatives for the non-generation of waste, and the circular economy is a means to achieve this goal. Among the pillars of the circular economy, ecodesign and reverse logistics are the most important for the circularity of products and the reuse of material. In this context, the study aims to analyze the application of reverse logistics and the concept of ecodesign in the development of footwear in the Brazilian footwear sector. As for the methodology, the research is classified as descriptive, qualitative multiple case study. The results show that the footwear sector does not adopt reverse logistics, and does not apply the concept of ecodesign in the development of footwear. The perception of the sector is that the footwear does not present environmental impacts, in addition, due to the difficulty of reusing the product, there is no interest on the part of the companies in making the return of the footwear to the manufacturer viable.

Keywords: Footwear sector. Environmental sustainability. Sustainable design. Reuse. Waste management.

\footnotetext{
${ }^{1}$ Autora correspondente. Universidade Feevale. RS-239, 2755 - Vila Nova. Novo Hamburgo/RS, Brasil. CEP 93525-075. http://lattes. cnpq.br/9221888421323687. https://orcid.org/0000-0002-8794-5271. marga_vier@hotmail.com

2 Universidade Feevale. Novo Hamburgo/RS, Brasil.
} 


\section{INTRODUÇÃO}

O setor calçadista causa impacto ambiental devido à quantidade de resíduos poluentes gerados e pelo pouco reaproveitamento do material, o que significa que praticamente todo o material utilizado na fabricação, inclusive o próprio produto fabricado, é enviado aos aterros sanitários e industriais (ALVES; BARBOSA, 2013; SOARES; ARAÚJO, 2016; ALBANIO; TATSCH, 2016). Esta é uma realidade não apenas no Brasil, mas também em diversos países da Europa, Ásia e América do Norte (ZAVODNA; TREJTNAROVA; POSPISIL, 2020).

Não se pode negar que as tendências da moda apontam para um consumo mais consciente e sustentável, incentivando o uso compartilhado de roupas e calçados, o que contribui para amenizar os impactos decorrentes do consumo desenfreado da população, e consequentemente, com destaque para a geração de resíduos (ZORTÉA, 2019). No que se refere ao setor calçadista, no entanto, o produto, mesmo que tenha sua vida útil prolongada por meio do reuso, haverá um momento em que sua reutilização não será mais possível, em virtude de seu desgaste natural, o que torna inevitável a geração de resíduos neste setor.

Considerando a ampla quantidade de resíduos gerados no setor, dos quais grande parte é classificada como sendo resíduos de Classe I - Perigosos - não basta reduzir a geração, é necessário alternativas para a não geração de resíduos, com a economia circular constituindo um meio para se alcançar este objetivo. O conceito de economia circular visa a fechar o ciclo de vida dos produtos, para que, ao final de sua vida útil eles possam ser reaproveitados, reutilizados ou reciclados, gerando assim benefícios econômicos, sociais e ambientais.

Entre os pilares da economia circular, o ecodesign e a logística reversa são os mais importantes para que se tenha esta circularidade dos produtos e da matéria-prima. Isto porque a não geração de resíduos no setor calçadista envolve não somente o material utilizado no calçado, mas também toda a cadeia produtiva. Assim sendo, é necessário avaliar o material usado no desenvolvimento do produto, analisar a matéria-prima fornecida e o descarte adequado do produto, para que este retorne à cadeia produtiva. São pontos relevantes e que podem ser meIhorados por meio da adequada aplicação do ecodesign e da logística reversa. Diante disso, o estudo busca responder ao seguinte problema de pesquisa: Qual é o nível de adoção de práticas de ecodesign e logística reversa, no âmbito da economia circular, nas indústrias de calçados brasileiras?

O estudo tem por objetivo analisar a aplicação da logística reversa e do conceito de ecodesign no desenvolvimento do calçado no setor calçadista brasileiro. Quanto à metodologia, a pesquisa é descritiva, e a abordagem do problema é qualitativa. Em relação aos procedimentos técnicos, o trabalho consiste na realização de estudo de caso múltiplo em empresas situadas no Vale do Rio dos Sinos e no Vale do Paranhana, regiões pertencentes ao Estado do Rio Grande do Sul, distantes aproximadamente 50 quilômetros da capital, Porto Alegre. As empresas estudadas destacam-se na produção de calçado, consequentemente, a quantidade de resíduos gerados também é elevada. Além disso, o estudo se propõe a contribuir com a literatura sobre a logística reversa e o ecodesign no contexto da economia circular. Após esta introdução, o estudo apresenta a fundamentação teórica, seguida dos procedimentos metodológicos, análise e discussão dos resultados, e, por fim, são apresentadas as considerações finais. 


\section{FUNDAMENTAÇÃO TEÓRICA}

Nesta seção é apresentada a fundamentação teórica acerca do tema do presente estudo. $O$ assunto está subdividido em três itens: primeiramente as premissas básicas sobre a economia circular, em seguida a logística reversa e finaliza-se com o texto acerca do ecodesign no setor calçadista.

\section{Economia Circular}

O conceito de economia circular é baseado no funcionamento da própria natureza, na qual não há a geração de resíduos. Sendo assim, é um modelo circular de produção, em que os recursos são repetidamente utilizados, reduzindo o consumo de matéria-prima e a geração de resíduos (LEITÃO, 2015; HOUSE OF COMMONS, 2014). A economia circular está voltada ao desenvolvimento sustentável, que por meio da inovação e do design, visa "fechar o ciclo de vida" dos produtos e aumentar a eficiência no uso dos recursos naturais, gerando benefícios econômicos, sociais e ambientais (LEITÃO, 2015; GHISELLINI; CIALANI; ULGIATI, 2016; KORHONEN; HONKASALO; SEPPÄLÄ, 2017).

Nesta perspectiva, os produtos são desenvolvidos para que ao final do primeiro ciclo eles possam ser utilizados como matéria-prima para um novo produto, iniciando um novo ciclo. Desse modo, os recursos naturais, ora limitados, são reaproveitados, agregando valor econômico e diminuindo a necessidade de extração dos recursos na natureza (STAHEL, 2016). Mostaghel e Oghazi (2018) enfatizam ainda a importância de cada um dos envolvidos no ciclo de vida dos produtos, pois se um deles não adotar o modelo circular esse produto encerra o seu ciclo, tornando-se apenas resíduo descartado.

A economia circular é representada em forma de círculos. A Ellen MacArthur Foundation (2012) cita que quanto maior o número de ciclos consecutivos a que o produto é submetido, maior o valor agregado da matéria-prima. Korhonen, Honkasalo e Seppälä, (2017) corroboram que o tempo no qual os produtos são submetidos nos círculos internos (reutilização, renovação e reparação), deve ser maximizado, exigindo menos recursos e energia, além de ser uma reciclagem mais econômica. Ellen MacArthur Foundation (2015) destaca ainda o poder dos insumos puros para prolongar o ciclo de vida de um material ou produto, ou seja, a importância de se utilizar a matéria-prima sem misturar com outros materiais que irão dificultar a separação por ocasião da reciclagem. Outra forma de agregar valor ao produto é por meio do uso em cascata, quando ocorre uma diversificação na reutilização do produto.

De acordo com Peron e Zoccoli (2017), para que se possa valorizar o produto e acrescentar valor à matéria-prima, é necessário focar no gerenciamento de materiais, e não na reciclagem. $O$ gerenciamento inclui planejar todo o ciclo de vida do material, antes mesmo de a matéria-prima ser extraída da natureza, no entanto não se pode menosprezar a importância da reciclagem para a diminuição dos resíduos, o que também é um dos objetivos da economia circular, porém a prioridade, na maioria dos casos, deve ser a recuperação dos produtos por meio da remanufatura. Sendo assim, o conceito de economia circular não deve ser sinônimo de reciclagem (PERON; ZACCOLI, 2017).

No que se refere à introdução da economia circular, os autores Mathews e Tan (2016) citam que a China foi o primeiro país a criar leis e adotar a economia circular e associam esta 
liderança ao fato de que é o país que mais consome recursos e produz resíduos, chegando, desta forma, ao limite, e sendo obrigado a tomar alguma providência. Os autores enfatizam ainda que o governo chinês reconheceu a economia circular como sendo o único meio de lidar com a exploração exagerada dos recursos, e incentivou as mudanças por meio de incentivos fiscais e políticas públicas (MATHEWS; TAN, 2016).

No início, muitos foram os esforços para desenvolver a economia circular na China, incluindo a produção mais limpa nas empresas, a inovação de processos com a redução no consumo de energia, a criação de parques industriais ecológicos e a reutilização ou reciclagem de resíduos durante os processos de fabricação (Ll et al., 2010). Além da China, cita-se a União Europeia, que teve avanços significativos no que respeita à economia circular, a começar pelo Pacote Economia Circular, anunciado em dezembro de 2015 pela Comissão Europeia (MATHEWS; TAN, 2016; FELDMANN et al., 2018).

Diferentemente da China e da União Europeia, o Brasil não possui um marco regulatório para a economia circular. Laurindo (2016), no entanto, destaca que, o que existe, são legislações para determinados segmentos ou pilares da economia circular, por exemplo, a Política Nacional de Resíduos Sólidos (PNRS), Lei no 12.305/10 (LAURINDO, 2016). A PNRS determina as diretrizes para a gestão dos resíduos sólidos e possui diversos pontos decisivos para a funcionalidade da economia circular. Entre estes pontos enfatiza-se a responsabilidade compartilhada pela destinação dos resíduos, o conceito de ciclo de vida de um produto e a obrigatoriedade de estruturar e instituir sistemas de logística reversa (BRASIL, 2010).

De acordo com Laurindo (2016), a economia circular no Brasil vem sendo difundida aos poucos, o que pode ser explicado justamente pela falta de legislação e políticas públicas específicas. Há, porém, outros conceitos largamente abordados e que contribuem para a consolidação do modelo de economia circular. Cita-se ainda a logística reversa e o ecodesign como conceitos essenciais na economia circular e que são reconhecidos no Brasil. O tópico seguinte aborda sobre o conceito de logística reversa.

\section{Logística Reversa}

A logística reversa é uma das ferramentas da economia circular, posto que é um instrumento que contribui para que os produtos retornem aos seus fabricantes e integrem novamente a cadeia produtiva, fechando o ciclo da matéria-prima. A Política Nacional de Resíduos Sólidos, Lei no 12.305 de agosto de 2010, define logística reversa como sendo um

instrumento de desenvolvimento econômico e social caracterizado por um conjunto de ações, procedimentos e meios destinados a viabilizar a coleta e a restituição dos resíduos sólidos ao setor empresarial, para reaproveitamento, em seu ciclo ou em outros ciclos produtivos, ou outra destinação final ambientalmente adequada (BRASIL, 2010).

A Ellen MacArthur Foundation (2015) apresenta a logística reversa como sendo um dos blocos que podem amenizar as barreiras encontradas e ajudar na introdução de uma economia circular. O desenvolvimento do produto pelo fabricante deve priorizar a sua reutilização após o uso, facultando que retorne, integralmente ou parcialmente, à cadeia de produção. Sendo assim, o ciclo reverso é tão importante quanto o design do produto, o modelo de negócio e os demais pilares da economia circular (ELLEN MACARTHUR FOUNDATION, 2015). 
Assim, a logística reversa é essencial na economia circular, justamente porque cria a obrigatoriedade dos consumidores, comerciantes, distribuidores e fabricantes, de operacionalizarem este ciclo inverso. $O$ grande desafio encontrado na gestão da logística reversa é o capital necessário para cobrir os custos de funcionamento do sistema, e também o comportamento do consumidor, fator-chave do ciclo reverso (WASTLING; CHARNLEY; MORENO, 2018). De acordo com Chaves, Balista e Comper (2019), o que motiva os fabricantes a adotarem processos de retorno dos produtos é a possibilidade de remanufatura e reciclagem. Além disso, um meio de contribuir para uma logística reversa eficiente é o fabricante incorporar ao produto, ou à sua embalagem, informações sobre o seu ciclo de vida, como pode ser reutilizado e como deve ser feito o seu descarte (PAGOROPOULOS; PIGOSSO; MCALOONE, 2017).

Quando não ocorre o retorno do produto ao seu fabricante (quando não se tem a logística reversa) faz-se necessário uma parceria entre as empresas para que se tenha a maior circularização de resíduos entre empresas de diferentes segmentos - o que é resíduo para uma, pode ser matéria-prima para outra (SANDOVAL; ORMAZABAL; JACA, 2017). Esta parceria, entre várias organizações interligadas, é denominada Simbiose Industrial. Em seu conceito, as indústrias devem operar de forma semelhante aos ecossistemas naturais, interagindo entre si, promovendo parcerias, como em uma comunidade (GIANETTI; ALMEIDA; BONILLA, 2003; SACIROVIC; KETIN; VIGNJEVIC, 2018).

Segundo Chertow (2000), a Simbiose Industrial envolve diferentes empresas em uma abordagem coletiva de vantagem competitiva, abrangendo a troca de materiais, subprodutos e energia. Ou seja, a Simbiose Industrial requer que o sistema industrial tenha uma visão sistêmica, em que empresas, inicialmente isoladas e de ramos distintos, atuam em conjunto, otimizando o ciclo de materiais, produtos e serviços. Sendo assim, os benefícios alcançados com o esforço coletivo são maiores do que aqueles que seriam alcançados de forma individual (CHERTOW, 2000).

A logística reversa é considerada uma das principais práticas de sustentabilidade das atividades de logística, e é parte integrante de uma abordagem maior, que é a logística verde (ENGELAGE; BORGERT; SOUZA, 2016). O conceito de logística compreende uma visão ampla da empresa e da cadeia de suprimentos, incorporando os processos de armazenagem, embalagem, transporte, carga e descarga, distribuição e definição de rede e atendimento ao cliente (ENGELAGE; BORGERT; SOUZA, 2016).

O fluxo de todas estas operações apresenta diferentes impactos ambientais, e, na busca por uma economia circular e sustentável, faz-se necessário a adoção de práticas ambientalmente adequadas, não somente no interior das empresas, mas em todo o processo logístico. De acordo com Engelage, Borgert e Souza (2016), são vários os componentes que impactam as atividades da logística verde e que formam o seu conceito, entre eles o design verde, as compras verdes, a armazenagem verde, a embalagem verde, a carga e descarga verde, o transporte verde, o marketing verde e a logística reversa.

A conscientização e a sensibilização da sociedade quanto à correta separação e destinação dos resíduos representam outro desafio para a economia circular e está relacionado à logística reversa. $O$ descarte incorreto inviabiliza a reutilização, recuperação ou, ainda, a reciclagem do material. Além disso, o próprio descarte dos resíduos é um grande problema, pois, ainda que exista uma legislação contemplando a responsabilidade compartilhada, não é o que acontece 
na prática. Velis e Vrancken (2015) destacam que o resíduo, uma vez descartado em local público por seu proprietário, é de todos e de ninguém ao mesmo tempo. Em razão da limpeza e da saúde pública, a responsabilidade por esse resíduo recai sobre o poder público, impossibilitando um sistema de logística reversa e fazendo com que as empresas deixem de se preocupar com o resíduo gerado de seus produtos.

A logística reversa, entretanto, aliada à conscientização e sensibilização da sociedade, só terá efeito no reaproveitamento dos materiais e diminuição do descarte de resíduos se este produto for projetado para a sua reutilização ou reciclagem. Sendo assim, a seguir aborda-se sobre o conceito de ecodesign.

\section{Ecodesign}

No tocante ao ecodesign, este está ligado diretamente à economia circular, pois tem como objetivo desenvolver produtos e serviços que reduzem o uso de recursos não renováveis, diminuindo os impactos ambientais. $O$ ecodesign visa utilizar matérias-primas que sejam recicláveis ou reaproveitáveis. É a arte de planejar um produto e já pensar no seu ciclo de vida, na forma com que ele será descartado ou reaproveitado no futuro (NAIME; GARCIA, 2004). 0 design do produto ameniza as barreiras na transição para uma economia circular, pois, para que o produto possa fechar o ciclo e voltar à cadeia produtiva, é necessário que ele seja projetado para este fim (ALVES; FREITAS, 2013; ELLEN MACARTHUR FOUNDATION, 2015).

O ecodesign é uma ferramenta de gestão ambiental com foco na concepção dos produtos e nos seus respectivos processos de produção, distribuição, utilização e descarte. Esta ferramenta tem por objetivo inovar os processos, produtos e serviços, com o intuito de reduzir a poluição e desenvolver produtos ecoeficientes. Alves e Freitas (2013, p. 204) destacam que o desenvolvimento de produtos ecoeficientes é "um processo que objetiva a junção do tecnicamente possível com o ecologicamente necessário, de forma que os impactos ambientais adversos decorrentes em toda fase de produção e ciclo de vida do produto possam ser mitigados".

O ecodesign envolve a escolha de materiais de baixo impacto ambiental, ou seja, menos poluentes, não tóxicos, materiais sustentáveis, recicláveis, ou que exigem menos energia na fabricação. O conceito busca minimizar o consumo de energia nos processos de fabricação e projetar materiais de qualidade, com maior durabilidade, diminuindo assim a geração de resíduos (MMA, 2019). Souza et al. (2017) destacam ainda que o ecodesign pode ser utilizado como uma ferramenta que auxilia na redução de custos, no reaproveitamento da matéria-prima e na diminuição dos desperdícios. Nesse sentido, a redução de custos é considerada um incentivo para que as empresas adotem e coloquem em prática este conceito em suas organizações.

$\mathrm{O}$ ecodesign busca utilizar materiais que possam ser reutilizados ou reciclados, materiais de fácil classificação, desmontagem, separação, ou que sejam úteis em outra cadeia produtiva, pois isto auxilia as empresas no reaproveitamento do produto ou na venda deste material. Por esta razão o ecodesign é um conceito essencial na economia circular e deve ser incentivado e introduzido em todas as empresas (ELLEN MACARTHUR FOUNDATION, 2015).

A indústria calçadista deve adotar os conceitos de ecodesign e economia circular, pois a vida útil do calçado é relativamente curta, e a maioria das empresas de reciclagem de couro, como as estabelecidas no Reino Unido, estão voltadas para a reciclagem do resíduo produzido durante o processo de fabricação. $O$ grande desafio ambiental do setor no contexto mundial são 
os resíduos gerados no pós-consumo (ZAVODNA; TREJTNAROVA; POSPISIL, 2020; RAHIMIFARD; STAIKOS; COATES, 2007).

A indústria portuguesa de calçado produz diversos resíduos que são enviados para aterros ou incinerados. Portugal produz e exporta mais de 50 milhões de pares de calçados por ano, e cada par gera em torno de 100 a 200 gramas de resíduos de couro (MARQUES; GUEDES; FERREIRA, 2017). O problema ambiental existe e deve ser enfrentado por todas as partes interessadas, principalmente empresas e consumidores. As empresas calçadistas devem valorizar as ações sustentáveis como sendo vantagens competitivas, e transformar este problema ambiental em uma oportunidade de novas soluções, envolvendo o design em várias dimensões e abordagens durante o processo produtivo (MARQUES; GUEDES; FERREIRA, 2017).

Albanio e Tatsch (2016) estudaram a percepção de empresas do setor calçadista sobre práticas sustentáveis e destacaram que alguns respondentes possuem conhecimento sobre o assunto, mas não o inserem na realidade da organização em razão de que os clientes não exigem ou não valorizam ações voltadas à sustentabilidade. Por sua vez, esses gerentes não sentem necessidades ou motivações para desenvolverem ações no sentido de promoverem os produtos fabricados com base nos aspectos sustentáveis. Nesse sentido, os autores afirmaram que em nenhum momento perceberam nos entrevistados a motivação para atuarem de maneira proativa e valorizar ações sustentáveis.

O estudo desenvolvido por Borchardt et al. (2011) mostra que práticas de ecodesign podem trazer diversos benefícios econômicos e ambientais. Os autores observaram que a prática do ecodesign durante o desenvolvimento do calçado reduziu os custos de fabricação em razão da substituição do material utilizado; os materiais tóxicos foram totalmente eliminados, e ainda, obteve-se uma redução no consumo de energia. Materiais alternativos, contudo, nem sempre são viáveis. Zavodna, Trejtnarova e Pospisil (2020) realizaram uma pesquisa para testar a viabilidade de um novo material para a indústria de calçados, desenvolvido na Índia e considerado biodegradável, porém os custos finais do produto tornaram-se elevados, o material não foi aceito pelos consumidores em virtude de seu desconforto, e o calçado não poderia ser comercializado mundialmente, pois suas características físicas variam de acordo com a temperatura da região.

Vários países enfrentam dificuldades com a falta de espaço físico para a destinação de resíduos. $O$ uso de materiais reciclados contribui para amenizar este problema (ZAVODNA; TREJTNAROVA; POSPISIL, 2020; RENSBURG; NKOMO; MKHIZE, 2020). A Adidas, fabricante mundialmente reconhecido na produção de roupas e calçados esportivos, iniciou um projeto que utiliza plástico reciclado na produção de seus calçados. É uma proposta de uma nova linha de tênis $100 \%$ reciclável. Foram lançadas, porém, apenas 200 unidades como parte de um programa-piloto, e serão testadas por pessoas selecionadas. A previsão é de que o produto somente será comercializado ao público em geral em 2021 (RENSBURG; NKOMO; MKHIZE, 2020; BARBOSA, 2019).

Outro fabricante de calçados reconhecido mundialmente e que possui um projeto de reciclagem é a Nike. O projeto, que ainda não foi introduzido no Brasil, inclui um sistema de coleta em que os calçados são encaminhados para uma central de reciclagem, são triturados e transformados em um material utilizado na pavimentação de quadras de tênis e basquete, ou pistas de corrida. A reciclagem do calçado convencional, no entanto, após sua vida útil, enfrenta di- 
versas dificuldades, uma vez que o calçado apresenta uma mistura de diversos materiais. Além disso, o sistema de recuperação do material depende do sistema de logística reversa, e que atualmente não possui infraestrutura viável para seu funcionamento (ZAVODNA; TREJTNAROVA; POSPISIL, 2020, RAHIMIFARD; STAIKOS; COATES, 2007, RENSBURG; NKOMO; MKHIZE, 2020).

Para que se tenha melhores resultados, o ecodesign deve ser aplicado juntamente com a Avaliação do Ciclo de Vida (ACV). A ACV é uma ferramenta para avaliar os impactos ambientais e as consequências à saúde humana associadas a um produto, serviço, processo ou material, ao longo de todo o seu ciclo de vida. É uma análise detalhada do ciclo de vida dos produtos, desde a extração e processamento da matéria-prima, sua transformação e beneficiamento, incluindo a utilização do produto e o descarte final. Por meio da ACV é possível quantificar e mensurar o impacto ambiental causado por determinado produto, ou até mesmo do modelo de negócio (SILVA et al., 2012; ASSIS, 2009). Na sequência estão detalhados os procedimentos metodológicos.

\section{PROCEDIMENTOS METODOLÓGICOS}

O presente estudo é de natureza aplicada, pois visa a aprimorar os conhecimentos de forma a contribuir com as práticas sustentáveis no setor calçadista. Quanto aos objetivos, a pesquisa é descritiva, pois busca descrever as práticas adotadas pelas empresas objeto de estudo de caso no que se refere à logística reversa e ao ecodesign no desenvolvimento do calçado, além de identificar, registrar e comparar os dados empíricos com os conceitos teóricos, a fim de aprofundar os conhecimentos acerca do tema estudado. A abordagem do problema é qualitativa (GIL, 2002).

Em relação aos procedimentos técnicos, o trabalho consiste na realização de pesquisa bibliográfica (GIL, 2002) e estudo de caso múltiplo (YIN, 2010). A pesquisa bibliográfica compreende a revisão teórica acerca das premissas básicas do conceito de logística reversa e ecodesign, no contexto da economia circular. A logística reversa e o ecodesign são dois dos diversos pilares que sustentam a economia circular. De acordo com os autores Laurindo (2016), Souza et al. (2017) e a Ellen MacArthur Foundation (2015), estes dois conceitos são a base para a introdução da economia circular, justificando, desta forma, a realização deste estudo, que oportuniza o aprofundamento dos conhecimentos acerca destes conceitos e suas aplicações práticas no setor calçadista brasileiro.

O estudo de caso foi aplicado em cinco indústrias do setor calçadista, escolhidas por conveniência e acessibilidade, quatro delas localizadas na região do Vale do Rio dos Sinos e do Vale do Paranhana, no Estado do Rio Grande do Sul, e uma localizada no Estado do Ceará. Por questões éticas e de sigilo, optou-se por não divulgar o nome das empresas participantes, as quais estão identificadas neste trabalho como empresa Alfa, Beta, Gama, AY e AZ. O sigilo também é um fator determinante na obtenção de respostas mais concretas e verdadeiras.

As empresas Alfa e AY são consideradas de grande porte; a empresa Beta, de acordo com o número de funcionários, é uma empresa de grande porte, porém é menor em relação às empresas Alfa e AY. A escolha pela empresa Beta deve-se ao fato de que ela foi fundada há mais de 65 anos, e, portanto, passou por diversas mudanças culturais e ambientais. A empresa Gama é considerada uma empresa de pequeno porte, familiar, e a empresa AZ é um atelier de calçados, que produz apenas a parte do pré-fabricado. A coleta de dados ocorreu por meio da triangulação de fontes: entrevistas semiestruturadas, observação não participante e levantamento documental. 
O roteiro para as entrevistas semiestruturadas foi elaborado com base na revisão bibliográfica. A partir do referencial teórico buscou-se identificar quais são os pontos relevantes para que se tenha a aplicação efetiva do ecodesign e da logística reversa, e então, as perguntas foram elaboradas com o intuito de verificar se estas práticas, elencadas na teoria, estavam sendo praticadas pelas empresas estudadas. As perguntas utilizadas nas entrevistas foram validadas, no mês de maio de 2019, por dois experts, seguindo a sistemática recomendada no método Delphi (WRIGHT; JOHNSON; BIAZZI, 1991). A seleção dos experts foi não aleatória, por conveniência e intencional.

A entrevista na empresa Alfa foi direcionada à técnica de segurança do trabalho, e também técnica em gestão ambiental, que trabalha no setor de segurança do trabalho, e que foi denominada, ao longo do trabalho, como sendo a Entrevistada A - EA. Nas empresas Beta e AY a entrevista semiestruturada foi aplicada aos gestores da produção, os quais são denominados como sendo respectivamente o Entrevistado B - EB e o entrevistado AY - EAY. A entrevista na empresa Gama foi com uma das proprietárias da empresa, denominada Entrevistada G - EG. Já a entrevista na empresa $A Z$ foi realizada com uma funcionária que trabalha há muitos anos na empresa, denominada Entrevistada AZ - EA.

A entrevista semiestruturada, bem como a visitação in loco e a observação não participante, foram realizadas nas empresas Alfa, Beta e Gama. Na empresa AZ também foi realizada a visitação in loco e a observação não participante, porém a entrevista semiestruturada foi aplicada parcialmente, considerando que, por ser um atelier de calçados, a empresa não desenvolve todos os processos, e, portanto, algumas perguntas não se aplicavam. Na empresa AY não ocorreram a visitação in loco nem a observação não participante, pois o entrevistado que aceitou responder às questões trabalha na filial situada no Ceará, e, portanto, a entrevista semiestruturada foi realizada via Skype. As entrevistas foram realizadas com hora marcada, nos meses de agosto e setembro de 2019, com duração média de 3 horas. Ao longo das entrevistas foram citados diversos documentos que, posteriormente, foram disponibilizados aos pesquisadores para incorporar à coleta de dados, por exemplo, a planilha de resíduos industriais gerados.

Em relação à análise dos dados, estes foram submetidos à análise de conteúdo, segundo Bardin (2011). As categorias utilizadas na coleta de dados, e posteriormente, na análise de conteúdo, foram, inicialmente: Logística Reversa e Ecodesign. Tais categorias foram subdivididas em duas outras:

a) Logística Reversa: i) o que é feito no setor calçadista para que se tenha o retorno do calçado ao fabricante; ii) qual o ciclo de vida do calçado; iii) quais produtos são devolvidos aos fornecedores por meio da logística reversa; iv) quais produtos/matéria-prima são provenientes de outra cadeia produtiva; v) quais resíduos da empresa são destinados para outra cadeia produtiva; vi) simbiose industrial.

b) Ecodesign: i) aplicação do conceito no desenvolvimento do produto; ii) características analisadas no desenvolvimento do calçado; iii) critérios utilizados na escolha dos materiais; iv) barreiras enfrentadas no reaproveitamento do produto (calçado) no próprio processo produtivo; v) avaliação do ciclo de vida do produto.

Ainda em relação à análise dos dados, os resultados foram semelhantes nas empresas estudadas, e, portanto, a análise foi feita em relação ao setor calçadista, e não de forma individualizada para cada empresa objeto do estudo de caso. Sendo assim, os resultados a seguir 
foram descritos por categoria de análise, apresentando-se os dados empíricos coletados no setor, agrupando os que foram análogos e destacando as peculiaridades de cada empresa estudada.

\section{ANÁLISE E DISCUSSÃO DOS RESULTADOS}

Neste tópico são apresentados os resultados da pesquisa. Primeiramente, a análise sobre a logística reversa no setor calçadista, e em seguida, a aplicação do conceito de ecodesign no desenvolvimento do calçado nas empresas estudadas.

\section{Logística reversa no setor calçadista}

A Ellen MacArthur Foundation (2015) apresenta a logística reversa como sendo um dos blocos que podem amenizar as barreiras encontradas e ajudar na efetivação de uma economia circular. Em relação à logística reversa nas empresas participantes do estudo, todos os entrevistados responderam que as empresas não viabilizam o retorno do produto ao final de sua vida útil. Relataram ainda que, no setor calçadista, esta prática nunca foi proposta ou debatida, e que não há uma preocupação por parte dos fabricantes com a destinação final do calçado. O EAY salientou ainda que, na percepção pessoal dele, o calçado, atualmente, não é considerado um produto que esteja agredindo o meio ambiente, e por esta razão, "não entrou na onda da logística reversa como as pilhas, lâmpadas e pneus".

Perguntou-se então qual a possibilidade de a empresa reutilizar o calçado, ou parte dele, no processo produtivo da empresa, na fabricação de novos calçados, para que a matéria-prima inicie um novo ciclo, conforme citado por Stahel (2016). Todos responderam que não é possível o reaproveitamento do calçado no processo produtivo, principalmente em virtude da dificuldade de separação dos componentes. De acordo com Ghisellini, Cialani e Ulgiati (2016), portanto, não há o "fechamento do ciclo de vida" do produto. O entrevistado da empresa AY destacou que cada modelo de calçado utiliza diferentes materiais, e que não é possível separar a matéria-prima de cada um deles, o que, consequentemente, impossibilita a reutilização ou a reciclagem do produto. As empresas disseram ainda que, quando precisam descartar um calçado pronto/ acabado, este é enviado ao coprocessamento, pois não reaproveitam o material.

Observa-se que a situação das empresas brasileiras é semelhante à das outras empresas internacionais. O grande desafio ambiental do setor são os resíduos do calçado no pós-consumo, citado por Zavodna, Trejtnarova, Pospisil (2020) e Rahimifard, Staikos e Coates (2007), ou então, quando o produto está acabado. Neste contexto, cita-se que inclusive a Nike, fabricante reconhecido mundialmente, também não reutiliza os calçados coletados no sistema de logística reversa, observando-se que, assim como as empresas objeto de estudo de caso, a Nike envia os calçados acabados para serem triturados e transformados em um material utilizado na pavimentação de quadras de tênis e basquete, ou pistas de corrida, conforme citado pelos autores Rahimifard, Staikos e Coates (2007) e Rensburg, Nkomon e Mkhize (2020).

De acordo com Stahel (2016), em uma economia circular os produtos são desenvolvidos para que ao final do primeiro ciclo eles possam ser reutilizados como matéria-prima para um novo produto, iniciando um novo ciclo. Nesta perspectiva, e considerando o relato das empresas descrito anteriormente, observa-se que o setor calçadista ainda precisa melhorar o processo 
de desenvolvimento do produto, pois, conforme enfatizaram Mostaghel e Oghazi (2018), quando um dos envolvidos no ciclo de vida de um produto não adota o modelo circular, este produto encerra o seu ciclo, tornando-se apenas resíduo descartado.

Tendo em vista que nas empresas estudadas o calçado não pode ser reaproveitado como matéria-prima na fabricação de novos calçados, a logística reversa nestas empresas é considerada apenas um custo, tanto para viabilizar o retorno do produto quanto para a destinação ambientalmente correta. Conforme citaram Chaves, Balista e Comper (2019), o que motiva os fabricantes a adotarem processos de retorno dos produtos é a possibilidade de remanufatura e reciclagem. Assim sendo, as empresas irão viabilizar o retorno do calçado quando estiverem obrigadas pela legislação. Isso porque, conforme Wastling, Charnley e Moreno (2018), o grande desafio encontrado na gestão da logística reversa é o capital necessário para cobrir os custos de funcionamento do sistema.

Ainda, no entanto, que o produto não possa retornar à cadeia produtiva, ser reciclado ou reutilizado, a Política Nacional de Resíduos Sólidos (PNRS), Lei no 12.305/10, prevê não só a obrigatoriedade de as empresas estruturarem e aplicarem sistemas de logística reversa, mas também, a responsabilidade compartilhada pela destinação dos resíduos. Ainda, no entanto, que exista uma legislação contemplando a responsabilidade compartilhada, não é o que acontece na prática. Todas as empresas participantes do estudo afirmaram que não se preocupam com o descarte final do produto que elas fabricam - o calçado - e ainda, nenhuma delas orienta os consumidores sobre qual seria a destinação correta do produto após o uso.

Nesse contexto, a destinação correta do calçado após o consumidor final utilizá-lo recai sobre o poder público, pois todos os calçados fabricados pela indústria calçadista têm como consumidor final as pessoas físicas, e estas descartam seus resíduos juntamente aos resíduos domésticos coletados pelos municípios. Esta prática comum é destacada pelos autores Velis e Vrancken (2015) quando afirmam que o resíduo, uma vez descartado em local público por seu proprietário, é de todos e de ninguém ao mesmo tempo. Em razão da limpeza pública, a responsabilidade deste resíduo recai sobre o poder público, impossibilitando um sistema de logística reversa e fazendo com que as empresas deixem de se preocupar com os resíduos gerados de seus produtos.

Com base nisso, procurou-se a cooperativa de recicladores do município de Dois Irmãos/ RS, onde situam-se três das cinco empresas estudadas, para saber sobre os calçados e a sua destinação final. De acordo com um dos cooperados, "é grande a quantidade de calçados que são descartados pelos munícipes e que chegam até a cooperativa todos os dias". Citou ainda que, atualmente, o calçado não é considerado um resíduo reciclável, e, portanto, todos os calçados são enviados ao aterro sanitário, junto com os demais resíduos orgânicos e não recicláveis. O que, segundo Peron e Zoccoli (2017), é ocasionado pela falta de gerenciamento dos materiais na etapa de desenvolvimento do produto, resultando na perda de valor agregado da matéria-prima.

De acordo com Korhonen, Honkasalo e Seppälä, (2017), quando não é possível reciclar o produto, az-se necessário maximizar o tempo no qual eles são submetidos nos círculos internos (reutilização, renovação e reparação). Conforme o entrevistado da cooperativa, antes de enviarem os calçados ao aterro sanitário, eles fazem uma breve triagem, retirando da esteira os 
calçados que estão em bom estado de conservação, e que podem ser reaproveitados, os quais são, então, distribuídos às pessoas da comunidade.

Mesmo havendo esta triagem, a quantidade de calçados destinada ao aterro sanitário é significativa, e é por isso que, conforme salientaram Rensburg, Nkomo e Mkhize (2020), vários países enfrentam dificuldades com a falta de espaço físico para a destinação de resíduos. 0 município de Dois Irmãos tem um pouco mais de 30 mil habitantes, e, em apenas três dias, os cooperados retiraram da esteira de triagem 603 calçados, o equivalente a 143 quilos, conforme apresentado na Figura 1. Além destes, têm-se ainda os calçados que foram retirados e que estavam em bom estado de conservação, e ainda, os que estão misturados aos resíduos orgânicos e que não passam pela esteira de triagem.

Figura 1 - Quantidade de calçados inutilizáveis recolhidos pela cooperativa de recicladores em três dias

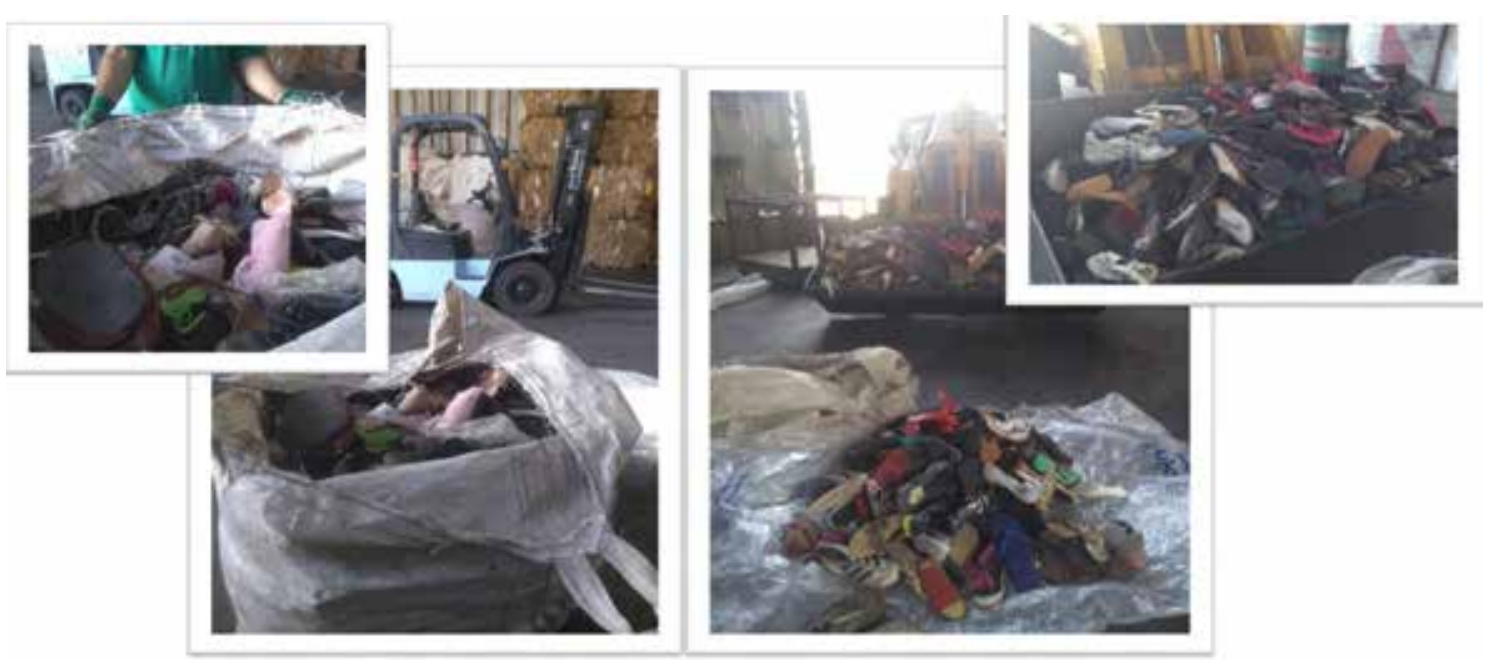

Fonte: VIER, 2020.

Conforme dados da Abicalçados (2018), analisando o mercado consumidor de calçados, o Brasil ocupa a quarta posição no ranking mundial, observando-se que no ano de 2016 foram consumidos 796 milhões de pares no país. Considerando que a destinação final do calçado é basicamente o aterro sanitário, em pouco tempo são 796 milhões de pares de calçados depositados nesses locais. Mesmo, portanto, que seja inviável economicamente e logisticamente o retorno do produto às empresas fabricantes, a indústria calçadista poderia utilizar o tratamento da indústria pneumática.

A resolução Conama 416, de 30 de setembro de 2009, que dispõe sobre a prevenção à degradação ambiental causada por pneus inservíveis e sua destinação ambientalmente adequada, obriga os fabricantes e importadores a destinarem corretamente $100 \%$ dos pneus que entram no mercado de reposição. A Associação Nacional da Indústria de Pneumáticos criou um sistema de coleta e destinação final ambientalmente adequada, com o custo deste sistema sendo repassado, então, aos fabricantes e importadores de pneus. Se a mesma legislação se aplicasse à indústria calçadista o calçado, ainda que não pudesse ser reaproveitado, teria uma destinação ambientalmente adequada que não fosse o aterro sanitário e este custo seria diluído e repassado ao consumidor final. 
O EB citou, porém, que, na percepção pessoal dele, todas as questões relacionadas ao meio ambiente evoluem gradativamente. Dito isto, é importante relatar que a responsabilidade compartilhada, no setor calçadista, começou a existir no que se refere às embalagens de calçado. Segundo a Associação Brasileira das Indústrias de Calçados - Abicalçados (2019) - as leis e normas ambientais determinam que os fabricantes, importadores, distribuidores e comerciantes devem garantir o recolhimento das embalagens de seus produtos, após o uso pelo consumidor, e esta legislação aplica-se, inclusive, às indústrias de calçados. Nesse sentido, a Abicalçados desenvolveu o Sistema de Logística Reversa de Embalagens para o Setor de Calçados, que tem como objetivo criar uma alternativa às empresas para o cumprimento das leis e normas ambientais, de forma eficaz, e com o menor custo possível.

De acordo com a Abicalçados (2019), o sistema, semelhante ao da indústria pneumática, é baseado na compensação ambiental das embalagens que o fabricante coloca no mercado, comprovando a reciclagem da quantidade equivalente, em massa e tipo de material. Na prática, a gestora do sistema capta recursos junto as empresas e os aplica em cooperativas de catadores e empresas de reciclagem. Com a publicação do Decreto Federal no 9.177, em 23 de outubro de 2017, todas as empresas do país que fornecem produtos com embalagens ficam submetidas às normas vigentes. O Ministério Público do Estado do Mato Grosso do Sul foi um dos primeiros a cobrar das empresas de todo o país a adoção do sistema de logística reversa de embalagens. De fato, os entrevistados da empresa Alfa, Beta e AY relataram que nas vendas realizadas ao Estado do Mato Grosso do Sul eles são obrigados a pagar determinado valor pela quantidade de pares vendidos, em razão da Logística Reversa das embalagens.

Ainda em relação à logística reversa, perguntou-se aos entrevistados quais eram os produtos, ou então, os resíduos por eles produzidos e que eram devolvidos aos seus fornecedores em cumprimento à Lei no 12.305 de 2010. De acordo com os entrevistados, todas as embalagens de substâncias químicas são recolhidas pelos respectivos fornecedores. A empresa AY e Alfa citaram ainda os restos de tinta e adesivos; e a empresa Beta mencionou as sobras de saltos $A B S$, pois é um material reaproveitável.

Considerando que a logística reversa está longe de ser uma realidade entre as empresas, a comercialização dos resíduos a outras empresas, de outros segmentos, é uma prática importante para a funcionalidade da economia circular. Conforme a Ellen MacArthur Foundation (2012), uma das formas de adicionar valor ao produto é por meio do uso em cascata, quando ocorre uma diversificação na sua reutilização. Sendo assim, questionou-se os entrevistados sobre quais são os materiais que a empresa utiliza, e que representam um subproduto do fornecedor; e ainda, quais são os materiais, resultantes do processo produtivo, que são comercializados a outras empresas, de outros segmentos.

De acordo com os entrevistados, as empresas não utilizam materiais resultantes do processo produtivo de algum outro segmento. E em relação aos resíduos que são comercializados como sendo matéria-prima a outras empresas de segmentos distintos, as empresas Gama e AZ não souberam responder, pois a gestão e destinação dos resíduos industriais é feita por uma empresa contratada.

As empresas Alfa, Beta e AY relataram que o couro, quando não está em contato com outras substâncias químicas (denominado couro limpo), é comercializado a uma empresa fabricante de adubo. A espuma é destinada a empresas fabricantes de estofados. A empresa Beta re- 
latou ainda que as navalhas utilizadas no setor da modelagem são comercializadas a empresas que fabricam navalhas, ou então, âncoras de navio. O couro "sujo" e outros materiais que não podem ser reciclados ou reaproveitados são enviados para o coprocessamento, em empresas que, basicamente, produzem cimento, porém enfatiza-se que, neste caso, esta destinação representa um alto custo para as empresas.

Observa-se que ocorre pouca comercialização de resíduos entre empresas. Uma forma de aumentar o fluxo de materiais e subprodutos entre as empresas, e aumentar a circularidade dos produtos, bem como a sua vida útil, é a criação de plataformas colaborativas. As plataformas colaborativas citadas pela Ellen MacArthur Foundation (2015) são plataformas virtuais de comunicação; é fazer o uso da tecnologia para facilitar o acesso à informação, rumo à economia circular. Estas plataformas podem conter informações acerca do reaproveitamento de diversos materiais e dispor de uma base de dados de compradores e fornecedores desses materiais.

Sandoval, Ormazabal e Jaca (2017) enfatizam a importância de ampliar as parcerias entre as empresas, para que se possa trabalhar a simbiose industrial. Os entrevistados relataram não haver parcerias entre as empresas do setor calçadista. Segundo Chertow (2000), as empresas, inicialmente isoladas e de ramos distintos, devem atuar em conjunto, otimizando o ciclo de materiais, produtos e serviços. Os entrevistados, no entanto, argumentaram que as empresas no setor calçadista são muito individualistas, e não saberiam trabalhar em conjunto. Observa-se que os parques industriais citados por Li et al. (2010), comuns na China, não teriam efetividade no Brasil. No que se refere à aplicação do ecodesign no desenvolvimento do calçado, os resultados são apresentados na sequência.

\section{Ecodesign na indústria calçadista}

O ecodesign é uma ferramenta de gestão ambiental com foco na concepção dos produtos e nos seus respectivos processos de produção, distribuição, utilização e descarte. Esta ferramenta tem por objetivo inovar os processos, produtos e serviços, com o intuito de reduzir a poluição e desenvolver produtos ecoeficientes (ALVES; FREITAS, 2013). A primeira pergunta direcionada aos entrevistados neste bloco de análise foi se as empresas aplicavam o conceito de ecodesign na etapa de concepção e modelagem. Todos os respondentes afirmaram que não aplicam o conceito na empresa.

Questionou-se então o porquê deste conceito não ser aplicado no desenvolvimento dos produtos. A EG relatou que a empresa não possui autonomia no desenvolvimento do calçado; que eles ficam restritos ao que o cliente solicita. Explicou ainda que a empresa recebe o modelo pronto, e que o modelista da fábrica apenas faz os ajustes técnicos. Nesse sentido o modelo, o formato de cada parte, o material utilizado e os enfeites alocados são definidos pelos clientes.

As empresas Alfa e Beta responderam que perdem um pouco da autonomia em relação às grandes marcas. A EA salientou que as marcas definem o modelo e indicam os materiais que devem ser utilizados, destacando que os modelistas apenas viabilizam estes materiais no modelo proposto, fazendo a construção do calçado. Novamente ressalta-se o que os autores Mostaghel e Oghazi (2018) enfatizam a importância de cada um dos envolvidos no ciclo de vida dos produtos.

Em relação às marcas próprias, o EB relatou que há um grande conflito entre moda e sustentabilidade. Acrescentou que são os estilistas que criam o modelo e definem o material, e 
que eles se baseiam nas tendências da moda. De fato, conforme Albanio e Tatsch (2016), o tema sustentabilidade ambiental e econômica promove uma certa inquietação ao relacionar-se com a moda, que historicamente tem seu mercado constituído pela constante evolução e pela cultura de consumo desenfreado.

O entrevistado da empresa Beta relatou ainda que a questão da sustentabilidade social, econômica e ambiental, na percepção dele, está evoluindo cada vez mais, porém está longe de ser uma economia circular. Neste momento, ele explica que os estilistas buscam criar modelos sustentáveis, no entanto, na percepção deles, a sustentabilidade ainda está relacionada ao uso de materiais que não contenham substâncias restritas; o que é diferente de materiais renováveis, ou recicláveis. Segundo o entrevistado, o setor calçadista vê a sustentabilidade como sendo o uso de substâncias não restritas, materiais que não são prejudiciais à saúde humana, e, principalmente, a correta gestão dos resíduos. Nesse contexto, os gestores consideram a empresa sustentável, contudo não no viés circular, até porque a economia circular ainda não é um conceito difundido e utilizado no setor calçadista.

Esta percepção do entrevistado em relação à sustentabilidade no setor calçadista, e principalmente a falta de ações efetivas no âmbito da sustentabilidade ambiental, corrobora os resultados do estudo de Albanio e Tatsch (2016), que evidenciaram que os gerentes não sentem a necessidade ou a motivação para desenvolverem ações no sentido de promoverem produtos fabricados com base nos aspectos sustentáveis, pois os clientes não valorizam tais ações. Os mesmos autores afirmaram que em nenhum momento perceberam nos entrevistados a motivação para atuarem de maneira proativa e valorizarem ações sustentáveis no setor calçadista, o que também foi observado ao longo das entrevistas do presente estudo.

Considerando que o ecodesign não é um conceito aplicado no desenvolvimento do calçado, solicitou-se aos entrevistados que enumerassem algumas características, de acordo com o grau de importância no desenvolvimento de um calçado. Tais características foram elencadas com base na revisão teórica e propostas pelos pesquisados aos entrevistados. O Quadro 1 apresenta, em ordem decrescente, as respostas de cada empresa. A empresa AZ não possui processo de desenvolvimento do calçado, e o entrevistado da empresa AY não quis ou não soube responder, pois o desenvolvimento do calçado ocorre na matriz, em outra localidade diferente daquela na qual ele trabalha.

Quadro 1 - Características analisadas no desenvolvimento de um calçado

\begin{tabular}{|c|c|c|c|}
\hline $\mathbf{x}$ & Alfa & Beta & Gama \\
\hline 1 & Aparência /Estética & Aparência /Estética & Exigências do Mercado \\
\hline 2 & Exigências do Mercado & Exigências do Mercado & Preço Baixo \\
\hline 3 & Conforto & Tendências da Moda & Conforto \\
\hline 4 & Preço Baixo & Conforto & Tendências da Moda \\
\hline 5 & Tendências da Moda & Preço Baixo & Aparência/Estética \\
\hline 6 & Matéria-Prima Reciclada & Matéria-Prima Reciclada & Matéria-Prima Reciclada \\
\hline 7 & Uso de Materiais Renováveis & Uso de Materiais Renováveis & Uso de Materiais Renováveis \\
\hline
\end{tabular}

Fonte: As autoras.

Observa-se que a Gama, por ser uma empresa de menor porte e que precisa competir com os concorrentes, colocou à frente os critérios de exigência do mercado e preço baixo, e na sequência o conforto, tendências da moda e aparência. Mesmo que a empresa atenda às clas- 
ses A e B, o preço baixo e o mercado ainda são mais relevantes em razão da concorrência. Já as empresas Alfa e Beta consideram a aparência e as exigências do mercado como características fundamentais. A empresa Beta, que produz um calçado mais voltado para a moda, enumerou as tendências como sendo o terceiro critério, depois o conforto e o preço baixo. Já a empresa Alfa produz calçados esportivos e consequentemente o conforto e o preço baixo estão acima da moda. Vale destacar que em todas as empresas as características "matéria-prima reciclada" e "uso de materiais renováveis" foram consideradas as menos importantes.

A Ellen Macarthur Foundation (2015) enfatiza ainda que o ecodesign busca utilizar materiais que possam ser reutilizados ou reciclados, materiais de fácil classificação, desmontagem, separação, ou que sejam úteis em outra cadeia produtiva, pois isto auxilia as empresas no reaproveitamento do produto ou na venda deste material. Nesse sentido, uma das perguntas direcionadas aos entrevistados foi justamente quais as barreiras enfrentadas no desenvolvimento de um calçado que utilize materiais que possam ser reaproveitados no processo produtivo da própria empresa, após o descarte. E ainda, qual a dificuldade de utilizar materiais recicláveis e renováveis no desenvolvimento de um calçado, uma vez que na questão anterior estas características foram consideradas as menos importantes no desenvolvimento do calçado.

Para os entrevistados, a maior barreira em reutilizar o calçado no processo produtivo, após o descarte, é a separação das partes e dos materiais. Esta barreira também foi apontada pelos autores Zavodna, Trejtnarova e Pospisil (2020) e Rahimifard, Staikos e Coates (2007) por dificultar a reciclagem do calçado convencional. A empresa Alfa relatou que a palmilha, por exemplo, é fabricada apenas com tecido e espuma, e que estes materiais são prensados. No caso da palmilha, tanto a espuma quanto o tecido são materiais recicláveis, porém a palmilha, depois que é prensada, não pode mais ser reaproveitada e é enviada ao coprocessamento. 0 mesmo ocorre com a borracha do solado. Durante a fabricação as rebarbas recortadas são reaproveitadas na fabricação de novos solados. Depois de pronto o solado é vulcanizado, impossibilitando a reutilização da borracha.

A Ellen MacArthur Foundation (2015) aponta para o poder dos insumos puros para prolongar o ciclo de vida de um material ou produto e enfatiza a importância de se utilizar a matéria-prima sem misturar com outros materiais que irão dificultar a separação na hora da reciclagem. Considerando os relatos anteriores, portanto, o setor calçadista ainda pode melhorar no que se refere aos insumos puros e à possibilidade de fechar o ciclo do produto.

A Ellen MacArthur Foundation (2015) salienta que o ecodesign visa a utilizar matérias-primas que sejam recicláveis ou reaproveitáveis. Em relação à dificuldade de se utilizar materiais recicláveis e renováveis no desenvolvimento de um calçado, os entrevistados relataram diversos fatores. A EA observou que eles fabricam um modelo que é único, e, portanto, a estrutura e o material utilizado são características do calçado, o que dificulta o uso de algum outro material que seja reciclável.

A empresa Beta enfatizou, novamente, que a preocupação pelo uso de matéria-prima reciclada, ou proveniente de algum outro segmento, não é pauta no setor calçadista. A prioridade é utilizar materiais livres de substâncias restritas, e que se este material é ou não fabricado com o uso de matéria-prima reciclada não é um critério de escolha. Além do mais, o entrevistado citou ainda que, por não ser um critério de escolha, os fornecedores não se preocupam em ofertar material reciclado, ou seja, mesmo que a empresa opte por utilizar material reciclado, 
não haveria muitos fornecedores na cadeia calçadista. Nesse sentido, os autores Peron e Zoccoli (2017) destacam que para não haver a produção de resíduos é necessário gerenciar toda a cadeia produtiva.

Outro fator descrito pelos entrevistados, e que dificulta o uso de material reciclado ou renovável, são os critérios estabelecidos pelas marcas. A EA explanou que as marcas são muito exigentes no tipo de material utilizado, que todos os fornecedores das grandes marcas precisam estar homologados, e para isso, são submetidos a diversos testes de laboratório, para análise de substâncias restritas ou que possam prejudicar o ser humano, além de testes sobre a qualidade e durabilidade do material. Muitos materiais, portanto, quando reciclados, podem até ser de qualidade, contudo são reprovados nestes testes realizados pelas marcas.

Conforme os dados coletados, a cadeia de suprimentos no setor calçadista carece de materiais compatíveis com a economia circular. O que se observa na literatura é que de fato são poucos os materiais provenientes de matéria-prima reciclada, ou então, materiais recicláveis ou biodegradáveis, disponíveis para o setor calçadista. Há estudos, como a pesquisa desenvolvida por Zavodna, Trejtnarova e Pospisil (2020), em que os autores testaram a viabilidade de um novo material para a indústria de calçados, desenvolvido na Índia e considerado biodegradável. Os custos finais do produto, no entanto, tornaram-se elevados, o material não foi aceito pelos consumidores em razão de seu desconforto e o calçado não poderia ser comercializado mundialmente, pois suas características físicas variam de acordo com a temperatura da região. Desse modo, os poucos materiais alternativos disponíveis não são viáveis para produção em grande escala.

O mesmo ocorre com o uso de materiais recicláveis. De acordo com os entrevistados, o uso destes não é critério na escolha do material, em virtude do custo elevado e da qualidade duvidosa. Nos casos das empresas Alfa e Beta, quem define os materiais a serem utilizados são as marcas com quem eles trabalham. Considerando que são marcas internacionais, estes critérios não são uma realidade somente nas empresas brasileiras. Sendo assim, o setor calçadista carece de estudos e do desenvolvimento de materiais alternativos, materiais recicláveis e de qualidade, com um custo viável para a produção em grande escala. A Adidas, por exemplo, possui uma proposta de uma nova linha de tênis $100 \%$ reciclável. De acordo com Barbosa (2019), o produto ainda está em fase de testes e não está sendo comercializado ao púbico em geral.

Silva et al. (2012) e Assis (2009) salientam que, para que se tenha melhores resultados, o ecodesign deve ser aplicado juntamente com a Avaliação do Ciclo de Vida (ACV), que é uma ferramenta para avaliar os impactos ambientais e as consequências à saúde humana associadas a um produto, serviço, processo ou material, ao longo de todo o seu ciclo de vida. Todos os entrevistados, contudo, afirmaram que as empresas nunca fizeram a Análise do Ciclo de Vida do calçado.

\section{CONSIDERAÇÕES FINAIS}

Em resposta ao objetivo geral, que foi analisar a aplicação da logística reversa e do conceito de ecodesign no desenvolvimento do calçado no setor calçadista brasileiro, constatou-se que este o setor não adota a logística reversa e também não aplica o conceito de ecodesign no desenvolvimento do calçado. A percepção do setor é que o calçado não apresenta impactos am- 
bientais e além disso, em razão da dificuldade de reciclagem ou reaproveitamento do produto, não há interesse por parte das empresas em viabilizarem o retorno do calçado ao fabricante. Sendo assim, o calçado é descartado como resíduo sólido urbano, na maioria das vezes em aterros sanitários.

Em relação ao setor de desenvolvimento do calçado, o estudo identificou que as empresas não aplicam o conceito. Isso ocorre porque não se faz necessário desenvolver um produto que possa ser reutilizado no processo produtivo, uma vez que as empresas do setor calçadista não são obrigadas a aplicar a logística reversa. Além disso, o setor calçadista não utiliza como critério de escolha da matéria-prima, materiais recicláveis ou renováveis, apenas os que não possuem substâncias restritas. Observou-se, no entanto, que os profissionais do setor da modelagem perdem a autonomia na escolha dos materiais a serem utilizados na fabricação do calçado e que apenas viabilizam os materiais definidos pelo setor de criação.

O ecodesign e a logística reversa são conceitos interligados e interdependentes. Ambos fazem parte de uma cadeia de suprimentos, destacando-se que não é possível aplicar o ecodesign se não houver fornecedores compatíveis; e em contrapartida, não haverá investimentos neste segmento se não houver interesse por parte do consumidor, e também, a responsabilidade compartilhada por parte da empresa fabricante em relação à destinação final dos calçados pós-consumo.

Nesta perspectiva os resultados da pesquisa evidenciam que nas empresas investigadas a adoção de logística reversa não seria viável, por ser considerada apenas um custo para o fabricante. Faz-se necessário, portanto, investimentos em tecnologia que torne possível e viável economicamente o reaproveitamento do calçado após o término de sua vida útil, bem como no desenvolvimento de materiais recicláveis e reaproveitáveis. Além disso, há uma carência na legislação e fiscalização por parte do poder público. Uma vez que a adoção do sistema de logística reversa for uma obrigação para todos os fabricantes de calçados, estes poderão repassar estes custos aos clientes e consumidores.

No que se refere à gestão de resíduos, constatou-se que as empresas se preocupam com a correta destinação, porém falta a articulação entre as empresas e a reutilização para promover a reciclagem e o reaproveitamento dos materiais, tanto pelas empresas estudadas quanto por outras, de outros segmentos. Grande parte dos resíduos gerados na produção do calçado, hoje, é destinada ao coprocessamento. Na percepção dos gestores, a mudança necessária não está relacionada ao sistema produtivo, mas sim em toda a cadeia produtiva. Para haver uma maior circularidade dos produtos, faz-se necessário o fornecimento de materiais compatíveis com a economia circular, o desenvolvimento de calçados que se utilizam de materiais renováveis e recicláveis, o maior engajamento de todo o setor, e ainda, a conscientização dos consumidores.

Observou-se ainda a partir dos relatos dos entrevistados que essa não é uma realidade somente no Brasil. De acordo com a literatura, o grande problema ambiental do setor calçadista hoje é a geração de resíduos no pós-consumo e a falta de espaço físico para a destinação desses resíduos. São poucas as alternativas de reciclagem para o calçado acabado. Tanto a Nike quanto as empresas estudadas enviam os calçados para o coprocessamento. A economia circular, no entanto, representada em forma de círculos, busca maximizar o número de ciclos consecutivos, principalmente os internos - reutilização, renovação e reparação - para que se tenha redução de perdas de energia e um maior valor agregado da matéria-prima. O coprocessamento, mesmo 
que viável ambientalmente, não é o mais adequado dentro da economia circular; o que evidencia a importância de estudos no desenvolvimento de métodos de reciclagem e reutilização do calçado no pós-consumo.

Como contribuição desta pesquisa, diante da escassez de estudos sobre as práticas de economia circular no setor calçadista, o trabalho contribuiu para a ampliação do conhecimento acadêmico, a partir de evidências empíricas analisadas reflexivamente. E como contribuição prática o estudo fornece informações para os gestores organizacionais das indústrias calçadistas, por identificar as práticas mais relevantes e impactantes, que podem facultar a adoção do modelo de economia circular no referido setor.

\section{REFERÊNCIAS}

ABICALÇADOS. Associação Brasileira das Indústrias de Calçados. Relatório Setorial Indústria de Calçados Brasil 2018. 2018. Disponível em: https://drive.google.com/file/d/18atEww9qvlQeMu3EutWURtHdTcXFN CnQ/view. Acesso em: 20 maio 2018.

ABICALÇADOS. Associação Brasileira das Indústrias de Calçados. Logística Reversa Agora: uma solução Abicalçados. 2019. Disponível em: https://www.abicalcados.com.br/logisticareversa. Acesso em: agosto 2019.

ALBANIO, Lúcia dos Santos; TATSCH, Marcelo Pastoriza. A percepção de empresas do setor calçadista sobre práticas sustentáveis. Organizações em Contexto, São Bernardo do Campo, v. 12, n. 23, jan./jun. 2016. ISSN 1982-8756.

ALVES, Isabel Joselita Barbosa da Rocha; FREITAS, Lúcia Santana. Análise comparativa das ferramentas de gestão ambiental: produção mais Limpa x Ecodesign. In: LIRA, Waleska Silveira; CÂNDIDO, Gesinaldo Ataíde (org.). Gestão sustentável dos recursos naturais: uma abordagem participativa. Campina Grande: E. Universidade Estadual da Paraíba, 2013. 325 p. p. 193. ISBN 9788578792824.

ALVES, Vanessa Cintra; BARBOSA, Agnaldo Sousa. Práticas de gestão ambiental das indústrias coureiras de Franca-SP. Gestão da produção, São Carlos, v. 3, n 4, p. 883-898, 2013.

ASSIS, Bruno Bastos. Avaliação do ciclo de vida do produto como ferramenta para o desenvolvimento sustentável. 2009. 66 f. Monografia (Engenharia de Produção) - Universidade Federal de Juiz de Fora, Juiz de Fora, MG, 2009.

BARBOSA, Vanessa. Adidas lança tênis do futuro feito de um único material e $100 \%$ reciclável. Marketing Exame, abr. 2019. Disponível em: https://exame.com/marketing/adidas-lanca-tenis-do-futuro-feito-deum-unico-material-e-100-reciclavel/. Acesso em: 17 jan. 2021.

BARDIN, Laurence. Análise de conteúdo. São Paulo, SP: Edições 70, 2011. 279 p.

BORCHARDT, Miriam; WENDT, Marcos H.; PEREIRA, Giancarlo M.; SELLITTO, Miguel A. Redesign of a component based on ecodesign practices: environmental impact and cost reduction achievements. Journal of Cleaner Production, Elsevier, v. 19, p. 49-57, 2011.

BRASIL, Lei no 12.305, de 2 de agosto de 2010. Institui a Política Nacional dos Resíduos Sólidos. Disponível em: http://www.planalto.gov.br/ccivil_03/_ato2007-2010/2010/lei/I12305.htm. Acesso em: 28 jun. 2016. CHAVES, Gisele de Lorena Diniz; BALISTA, Wagner Cezario; COMPER, Indiana Caliman. Logística reversa: o estado da arte e perspectivas futuras. Engenharia Sanitária Ambiental, v. 24, p. 821-832, jul./ago. 2019.

CHERTOW, Marian R. Industrial Symbiosis: literature and taxonomy. Journals Annual Reviews, v. 25, p. 313337, Mar. 2000.

ELLEN MACARTHUR FOUNDATION. Towards a Circular Economy: Busines Rationale for an Accelerated Transiton. December, 2015. Disponível em: https://www.ellenmacarthurfoundation.org/publications

ELLEN MACARTHUR FOUNDATION. Towards a Circular Economy: Economic and business rationale for an accelerated transition. January, 2012. Disponível em: https://www.ellenmacarthurfoundation.org/ publications

ENGELAGE, Emanuele; BORGERT, Altair; SOUZA, Marcos Antônio. Práticas de Green Logistic: uma abordagem teórica sobre o tema. GeAS - Revista de Gestão Ambiental e Sustentabilidade, v. 5, n 3; p. 3655, E. Científica, set. 2016. DOI: 10.5585/geas.v5i3.446

FELDMANN, Andreas; KORHONEN, Jouni; NUUR, Cali; BIRKIE, Seyoum Eshetu. Circular Economy as na 
essentially contested concept. Journal of Cleaner Production, Elsevier, v. 175, p. 544-552, Feb. 2018DOI 10.1016

GHISELLINI, Patrizia; CIALANI, Catia; ULGIATI, Sergio. A review on circular economy: the expected transition to a balanced interplayofenvironmental and economic systems. Journal of Cleaner Production. Elsevier, v. 114, p. 11-32, Feb. 2016.

GIANNETTI, Biagio Fernando; ALMEIDA, Cecília M. Villas Boas de; BONILLA, Sílvia H. Implementação de eco-tecnologias rumo à ecologia industrial. Revista Administração de Empresas - RAE-Eletrônica, v. 2, n. 1, jan./jun. 2003.

GIL, Antônio Carlos. Como elaborar projetos de pesquisa. 4. ed. São Paulo, SP: Atlas, 2002. 175 p.

HOUSE OF COMMONS. Growing a circular economy: Ending the throwaway society. HC-214. Londres: House of Commons/ Environmental Audit Committee, July, 2014. Disponível em: https://publications. parliament.uk/pa/cm201415/cmselect/cmenvaud/214/214.pdf

KORHONEN, Jouni; HONKASALO, Antero; SEPPÄLÄ, Jyri. Circular Economy: The concept and its limitations. Ecological Economics, Elsevier, v. 143, p. 37-46, July 2017.

LAURINDO, Michelly. A viabilidade da economia circular à luz da Política Nacional de Resíduos Sólidos: Lei 12.305 de 2 de agosto de 2010. 2016. 62 f. Monografia (Ciências Econômicas) - Universidade Federal de Santa Catarina, Florianópolis, SC, 2016.

LEITÃO, Alexandra. Economia circular: uma nova filosofia de gestão para o séc. XXI. Portuguese Journal of Finance, Management and Accounting. v. 1, n 2, p. 149-171, Sept. 2015. ISSN: 2183-3826.

LI, Huiquan; BAO, Weijun; XIU, Caihong; ZHANG, Yi; XU, Hongbin. Energy conservationand circular economy in Chinas'process industries. Energy, Elsevier, v. 35, n. 11, p. 4.273-4.281, nov. 2010.

MARQUES, Antônio; GUEDES, Graça; FERREIRA, Fernando. Leather wastes in the Portuguese footwear industry: new framework according design principles and circular economy. Procedia Engineering, Elsevier, p. 303-308, June 2017. Disponível em: https://www.researchgate.net/publication/320370322 Leather_wastes_in_the_Portuguese_footwear_industry_new_framework_according_design_principles_ and_circular_economy.

MATHEWS, John A.; TAN, Hao. Lessons from China: The country consumes the most resources in the world and produces the most waste - but it also has the most advanced solutions. Nature Publishing Group, Macmillan Publishers Limited, v. 531, Issuee 7595, p. 440-442, Mar. 2016.

MMA - MINISTÉRIO DO MEIO AMBIENTE. Ecodesign. Disponível em: http://www.mma.gov.br/informma/ item/7654-ecodesign.html. Acesso em: 6 abr. 2019.

MOSTAGHEL, Rana; OGHAZI, Pejval. Circular Business Model Challenges and Lessons Learned - An Industrial Perspective. Journal Sustainability, MDPI AG, v. 10, n. 3, Mar. 2018. DOI: 10.3390/su10030739

NAIME, Roberto; GARCIA, Ana Cristina de Almeida. Percepção ambiental e diretrizes para compreender a questão do meio ambiente. Novo Hamburgo, RS: Feevale, 2004. 135 p.

PAGOROPOULOS, Aris; PIGOSSO, Daniela C. A.; MCALOONE, Tim C. The Emergent Role of Digital Technologies em the Circular Economy: A Review. CIRP IPSS CONFERENCE: CIRCULAR PERSPECTIVES ON PRODUCT/SERVICE-SYSTEMS, 9., Elsevier, v. 64, p. 19-24, 2017.

PERON, Jorge; ZOCCOLI, Carolina. Economia circular, uma evolução industrial. In: LUZ, Beatriz (org.). Economia circular - Holanda - Brasil - Da teoria à Prática. 1. ed. Rio de Janeiro: Exchange 4 Change Brasil, 2017. p. 29.

RAHIMIFARD, Shahin; STAIKOS, Theodoros; COATES, Gareth. Recycling of Footwear Products. Centre for Sustainable Manufacturing and Reuse/recycling Technologies - Smart, Dec. 2007.

RENSBURG, Melissa L. Van; NKOMO, S'phumelele, L.; MKHIZE, Ntandoyenkosi M. Life cycle and End-ofLife management options in the footwear industry: A review waste management and research. Journals Sagepub, v. 38, p. 599-613, 2020.

SACIROVIC, Selim; KETIN, Sonja; VIGNJEVIC, Nada. Eco-industrial zones in the contexto of sustainability development of urban áreas. Environmental Science and Pollution Research, Springer Verlag, p. 1-11, Mar. 2018. DOI: 10.1007/s11356-018-1390-y.

SANDOVAL, Vanessa Prieto; ORMAZABAL, Marta; JACA, Carmen. Towards a consensus on the circular economy. Journal of Cleaner Production, Elsevier; v. 179, p. 605-615, Dec. 2017.

SILVA, Christian Luiz da Silva; JUNIOR, Eloy Fassi Casagrande; LIMA, Isaura Alberton de; SILVA, Maclovia Corrêa da; AGUDELO, Líbia Patrícia Peralta; PIMENTA, Rosângela Borges. Inovação e sustentabilidade. Curitiba, PR: Aymará Educação, 2012. Disponível em: http://repositorio.utfpr.edu.br/jspui/bitstream/1/2066/1/ inovacaosustentabilidade.pdf. Acesso em: 25 abr. 2018.

SOARES, Eliseu Afonso; ARAÚJO, Geraldino. Gestão de resíduos sólidos no processo produtivo: um estudo 
de caso em uma indústria calçadista. Revista da Universidade Vale do Rio Verde, v. 14, n. 2, p. 171-181, ago./dez. 2016.

SOUZA, Fernando Bernardi; LUIZ, Octaviano Rojas; SILVA, Sergio Luis; JUGEND, Daniel; ANDRADE, João Leonardo; LUIZ, João Victor Rojaz. Adoção do ecodesign em empresas inovadoras no Brasil: levantamento e análise dos principais estímulos. Revista Produção On-line, Florianópolis, SC, v. 17, n. 2, p. 692-710, 2017. STAHEL, Walter R. Circular economy: a new relationship whit our goods and material swould save resources and energy and create local Jobs. Nature Publishing Group, Macmillan Publishers Limited, v. 531, p. 435438, Mar. 2016.

VELIS, Costas A.; VRANCKEN, Karl C. Which material owner shipand responsability in a circular economy? The Journal of the International Solid Wastes and Public Cleansing Association, Sage Publications, v. 33, n. 9, p. 773-774, Sept. 2015. ISSN: 1096-3669

WASTLING, Thomas; CHARNLEY, Fiona; MORENO, Mariale. Design for Circular Behaviour: considering users in a circular economy. Journal Sustainability, v. 10, 22 p., May. 2018. DOI: 10.3390/su10061743

WRIGHT, J. T. C.; JOHNSON, B. B.; BIAZZI, J. L. O uso da técnica Delphi na elaboração de cenários. São Paulo: Petrobras, 1991. $31 \mathrm{p}$.

YIN, Roberto K. Estudo de caso: planejamento e métodos. 4. ed. Porto Alegre, RS: Bookman, 2010. 248 p. ZAVODNA, Lucie Sara; TREJTNAROVA, Lucie; POSPISIL, Jan Zavodny. A sustainable materials for footwear industry: designing biodegradable shoes. Applied Researches in Technics, Technologies and Education ARTTE. Journal of the Faculty of Technics and Technologies, Trakia University, v. 8, n. 1, Feb. 2020. ISSN 1314-8796

ZORTÉA Fabiano Bassani. Compartilhamento de roupas: um novo comportamento de consumo. Moda Mercado, Sebrae 2019. Disponível em: https://sebraers.com.br/moda/compartilhamento-de-roupas-umnovo-comportamento-de-consumo/. Acesso em: 17 jan. 2021. 